\title{
Genetic structure of the genus Leptospira by multilocus enzyme electrophoresis
}

\author{
M. Letocart, ${ }^{1}$ P. Boerlin, ${ }^{2} \dagger$ F. Boerlin-Petzold, ${ }^{2}+$ J. Goudet, ${ }^{3}$ G. Baranton ${ }^{4}$ \\ and P. Perolat ${ }^{1}$
}

\begin{abstract}
Author for correspondence: P. Perolat. Tel: +687270280 . Fax: +687273390. e-mail: perolat.pasteur@canl.nc
\end{abstract}

\footnotetext{
1 Leptospira Laboratory, Institute Pasteur, BP 61 98846 Noumea Cedex, New Caledonia

2 Microbiology Institute of the University of Lausanne, 44 Bugnon St, $\mathrm{CH}-1011$ Lausanne, Switzerland

3 Institute of Animal Zoology and Ecology, University of Lausanne, Switzerland

4 WHO Collaborating Centre for Leptospirosis, Medical and Molecular

Bacteriology Unit, Institute

Pasteur, Paris, France
}

\begin{abstract}
Thirty strains from the 11 species of the genus Leptospira were studied by multilocus enzyme electrophoresis at 12 enzyme loci, all of which were polymorphic. The mean number of alleles per locus was 6.5. Twenty-five electrophoretic types were distinguished. Grouping of the strains by cluster analysis was in general agreement with species delineation as determined by DNA-DNA hybridization, except for the strains of Leptospira meyeri and Leptospira inadai, which were scattered throughout the genus, reflecting previously recognized taxonomic uncertainties. Analysis of the clonality within Leptospira interrogans sensu stricto indicated that this population was relatively heterogeneous and a lack of gene linkage disequilibrium could not be excluded. There was a genetic discrimination between the pathogenic species and the saprophytic ones. The phenotypically intermediate species ( $L$. inadai and Leptospira fainei) were also genetically separated and were probably closer to the saprophytes than to the pathogens.
\end{abstract}

Keywords: Leptospira, multilocus enzyme electrophoresis, genetics, phylogeny, taxonomy

\section{INTRODUCTION}

Bacteria of the genus Leptospira are the causative agent of leptospirosis, a worldwide zooanthroponosis (Johnson \& Faine, 1984). Virulence for susceptible animals is a differential character which led to the primary subdivision of Leptospira into two nomenspecies: Leptospira interrogans, including the pathogens, and Leptospira biflexa, comprising the nonpathogens. For epidemiological purposes, pathogenic isolates were further classified on serological grounds into 24 serogroups and more than 200 serovars (Dikken \& Kmety, 1978).

During the past decade, molecular taxonomy, especially DNA-DNA hybridizations, has greatly im-

\footnotetext{
†Present address: Department of Pathobiology, University of Guelph Ontario, Canada.

Abbreviations: $A C O$, aconitase; ADK, adenylate kinase; ALP, alkaline phosphatase; AP-PCR, arbitrarily primed PCR; CAT, catalase; ET(s), electrophoretic type(s); FUM, fumarase; GD2, glutamate dehydrogenase 2; IDH, isocitrate dehydrogenase; $\mathrm{MDH}$, malate dehydrogenase; MEE, multilocus enzyme electrophoresis; MPI, mannose-phosphate isomerase; MRSP mapped restriction site polymorphism; PEP, peptidase; PFGE, pulsed-field gel electrophoresis; PGI, phosphoglucose isomerase.
}

proved knowledge of the genus. These studies have shown that the two nomenspecies, $L$. interrogans and $L$. biflexa, are in fact a mixture of several genomic species: seven pathogenic species (Ramadass et al., 1992; Yasuda et al., 1987), Leptospira borgpetersenii, Leptospira inadai, L. interrogans sensu stricto, Leptospira kirschneri, Leptospira noguchii, Leptospira santarosai and Leptospira weilii, and three saprophytic species, L. biflexa sensu stricto, Leptospira meyeri and Leptospira wolbachii. Recently, an eighth pathogenic species, Leptospira fainei, was described (Perolat et al., 1998).

Other molecular approaches have been applied to taxonomic and epidemiological investigations of Leptospira genetics. These include restriction endonuclease analysis (Ellis et al., 1991), pulsed-field gel electrophoresis (PFGE) (Herrmann et al., 1991, 1992), ribotyping (Perolat et al., 1993), mapped restriction site polymorphism (MRSP) and arbitrarily primed PCR (AP-PCR) (Perolat et al., 1994; Ralph et al., 1993). Such methods have allowed characterization of the leptospires at the species and subspecies level.

However, the taxonomy of Leptospira needs to be studied further as some questions remain. (i) The 
Table 1. List of the Leptospira strains used in this study

\begin{tabular}{|c|c|c|c|c|c|}
\hline Genospecies & ET & Serovar & Strain & Serogroup & Origin \\
\hline \multirow[t]{2}{*}{ L. biflexa } & 22 & patoc & Patoc $1^{\mathrm{T}}$ & Sema & Italy (water) \\
\hline & 23 & andamana & CH11 & Anda & Andaman islands (human) \\
\hline \multirow[t]{4}{*}{ L. borgpetersenii } & 6 & javanica & Veldrat Batavia $46^{\mathrm{T}}$ & Java & Indonesia (rat) \\
\hline & 8 & ballum & Mus 127 & Ball & Denmark (mouse) \\
\hline & 7 & hardjo & Hardjobovis Sponselee & Sejr & Netherlands (cattle) \\
\hline & 9 & sejroe & M 84 & Sejr & Denmark (mouse) \\
\hline L. fainei & 24 & hurstbridge & But6 $^{\mathrm{T}}$ & Hurs & Australia (pig) \\
\hline \multirow[t]{2}{*}{ L. inadai } & 17 & lyme & $10^{\mathrm{T}}$ & Lyme & USA (human) \\
\hline & 18 & malaya & $\mathrm{H} 6^{*}$ & Cani & Malaysia (human) \\
\hline \multirow[t]{11}{*}{ L. interrogans } & 1 & icterohaemorrhagiae & $\mathrm{RGA}^{\mathrm{T}}$ & Icte & France (human) \\
\hline & 2 & autumnalis & Akiyami A & Autu & Japan (human) \\
\hline & 3 & bataviae & Van Tienen & Bata & Indonesia (human) \\
\hline & 1 & bratislava & Jez-Bratislava & Aust & Czechoslovakia (hedgehog) \\
\hline & 2 & canicola & Hond Utrecht IV & Cani & Netherlands (dog) \\
\hline & 21 & evansi & $267-1348$ & Rana & Malaysia (water) \\
\hline & 1 & hardjo & Hardjoprajitno & Sejr & Indonesia (human) \\
\hline & 4 & hebdomadis & Hebdomadis & Hebd & Japan (human) \\
\hline & 1 & lai & Lai & Icte & China (human) \\
\hline & 5 & pomona & Pomona & Pomo & Australia (human) \\
\hline & 3 & pyrogenes & Salinem & Pyro & Indonesia (human) \\
\hline \multirow[t]{2}{*}{ L. kirschneri } & 10 & cynopteri & $3522 \mathrm{C}^{\mathrm{T}}$ & Cyno & Indonesia (human) \\
\hline & 11 & grippotyphosa & Moskva V & Grip & Russia (human) \\
\hline \multirow[t]{2}{*}{ L. meyeri } & 19 & ranarum & $\mathrm{ICF}^{\mathrm{T} *}$ & Rana & USA (frog) \\
\hline & 20 & sofia & Sofia $874^{*}$ & Java & Bulgaria (human) \\
\hline \multirow[t]{2}{*}{ L. noguchii } & 12 & panama & $\mathrm{CZ} 214^{\mathrm{T}}$ & Pana & Panama (opossum) \\
\hline & 13 & cristobali & $1996 \mathrm{~K}$ & Pana & Panama (opossum) \\
\hline \multirow[t]{2}{*}{ L. santarosai } & 14 & shermani & $1342 \mathrm{~K}^{\mathrm{T}}$ & Sher & Panama (rat) \\
\hline & 15 & navet & TRVL 109873 & Tara & Trinidad (human) \\
\hline L. weilii & 16 & celledoni & Celledoni $^{\mathrm{T}}$ & Cell & Australia (human) \\
\hline L. wolbachii & 25 & codice & $\mathrm{CDC}^{\mathrm{T}}$ & Codi & USA (water) \\
\hline
\end{tabular}

* Identification of these strains is discussed in the text.

status of some strains, an even species, is uncertain, as in the case of $L$. meyeri reference strain (serovar ranarum strain ICF), for which controversial taxonomic results are provided in the literature: although it was reported to represent a new species by Yasuda et al. (1987), this strain was previously reported in numerous studies to be related to the pathogenic group (Brendle et al., 1974; Gravekamp et al., 1993; Hookey, 1992; Hookey et al., 1993; Letocart et al., 1997; Murgia et al., 1997; Segers et al., 1992). (ii) Though great diversity is evident within the genus, the degree of proximity of the strains within the species has been poorly investigated. (iii) Lastly, little information is available on the genetic distinction between the saprophytic and pathogenic species.

In order to investigate these questions, the genetic structure of the genus Leptospira was studied by multilocus enzyme electrophoresis (MEE), which has not previously been performed on these bacteria. This method allows the analysis of many loci, representing several different metabolic activities, at the same time
(Selander et al., 1986). MEE has a large spectrum of applicability and it can distinguish nearly clonal strains (Beutin et al., 1990; Boerlin, 1997; Patton et al., 1991; Yakrus et al., 1992) as well as different species of a genus (Altwegg et al., 1991; Boerlin et al., 1991, 1992). MEE and DNA-DNA hybridization are strongly correlated (Altwegg et al., 1991; Boerlin, 1997; Boerlin et al., 1991, 1992), so this study could attempt to determine whether uncertainties at the species level could be due to the method used or to discrepancies between reference collections.

\section{METHODS}

Bacterial strains. Thirty reference strains of leptospires were analysed (Table 1), including two $L$. biflexa, four $L$. borgpetersenii, one $L$. fainei, two L. inadai, 11 L. interrogans, two $L$. kirschneri, two $L$. meyeri, two $L$. noguchii, two $L$. santarosai, one $L$. weilii and one $L$. wolbachii. These bacteria were supplied initially by the WHO Collaborating Centre for Leptospirosis, Institute Pasteur, Paris, France, and subsequently maintained at the laboratory. Species assign- 
MEE analysis of genus Leptospira

ments are according to Brenner \& Kaufmann (1994), which is the last genomic classification available on the basis of DNA-DNA hybridization.

Culture conditions. Each strain was grown to stationary phase in $1.51 \mathrm{EMJH}$ medium (Ellinghausen \& McCullough, 1965 ) in the dark at $30^{\circ} \mathrm{C}$ with shaking.

Preparation of lysates and electrophoresis. Lysate preparation, electrophoresis in starch gels (Sigma) and selective staining were performed as described by Selander et al. (1986), except for catalase, which was stained by the method of Harris \& Hopkinson (1976). After testing more than 50 specific enzyme staining procedures and five different electrophoresis buffer systems, the following 12 enzymes and four buffer systems were chosen: buffer A, aconitase (ACO), adenylate kinase (ADK), fumarase (FUM), isocitrate dehydrogenase (IDH) and phosphoglucose isomerase (PGI); buffer $\mathrm{B}$, malate dehydrogenase (MDH) and mannosephosphate isomerase (MPI); buffer F, catalase (CAT) and peptidases 4 and 5 (PEP4 and 5, the respective substrates of which are Leu-Leu-Leu and Phe-Pro); and buffer G, alkaline phosphatase (ALP) and glutamate dehydrogenase 2 (GD2).

Statistical analysis of the data. Alleles were numbered in order of decreasing mobility and allele ' 0 ' represented a lack of detectable activity for the corresponding enzyme. Migration coefficients were unweighted. Under pure clonality, strong linkage disequilibrium should develop among loci. The GENEPOP software (Raymond \& Rousset, 1995) was used to test whether loci in L. interrogans were in linkage equilibrium. Genetic distances among electrophoretic types (ETs) were calculated as shared allele distances, which is considered a strong method for tree topology restitution (Takezaki \& Nei, 1996), and two trees were constructed using the neighbour-joining method (Saitou \& Nei, 1987) implemented in NEIGHBOR, part of the PHYLIP suite of programs (J. Felsenstein and University of Washington, 1991-1993), and the unweighted pair group method with averages (UPGMA).

\section{RESULTS}

\section{Genetic diversity at enzyme loci}

Table 2 summarizes the genetic diversities at the 12 loci, which were all polymorphic. The number of alleles at each locus varied from 3 (ACO, CAT and MDH) to 12 (PEP4), with a mean value of 6.5. The genetic diversity between alleles at a given locus was calculated according to the formula previously described by Selander et al. (1990). It varied from 0.35 (MDH) to 0.90 (PEP4) with a mean value of 0.63 (Table 2). L. kirschneri, L. inadai and L. meyeri had no monomorphic locus with a specific allele (Table 3 ). $L$. noguchii had specific monomorphic alleles for ALP and MPI, L. biflexa for GD2, PEP5 and PGI, L. weilii for ADK, ALP, MPI and PEP4, and L. wolbachii for FUM, MPI, PEP4 and PEP5 (these last two species were represented by one strain only). $L$. interrogans was monomorphic at the ALP locus and only shared this allele with $L$. inadai malaya $\mathrm{H} 6$ and $L$. meyeri ranarum ICF among the other species. It should be noted that these last strains did not cluster with their species on the dendrogram, but were instead included
Table 2. Genetic diversity at the 12 loci studied

\begin{tabular}{|lcc|}
\hline Locus* & $\begin{array}{c}\text { No. of } \\
\text { different alleles }\end{array}$ & Genetic diversity \\
\hline ACO & 3 & $0 \cdot 52$ \\
ADK & 7 & $0 \cdot 62$ \\
ALP & 8 & $0 \cdot 75$ \\
CAT & 3 & $0 \cdot 39$ \\
FUM & 5 & 0.45 \\
GD2 & 8 & 0.78 \\
IDH & 4 & 0.53 \\
MDH & 3 & 0.35 \\
MPI & 10 & 0.79 \\
PEP4 & 12 & 0.90 \\
PEP5 & 7 & 0.81 \\
PGI & 8 & 0.72 \\
Mean & 6.5 & 0.63 \\
\hline
\end{tabular}

* See Methods for locus abbreviations.

in L. interrogans (Figs 1 and 2). The same situation was observed for $L$. borgpetersenii with $L$. meyeri sofia Sofia 874 at the IDH and PEP5 loci.

No specific allele was identified that allowed the pathogens and saprophytes to be distinguished. However, a lack of detectable activity for ALP was evident in L. biflexa and L. wolbachii (but not in L. meyeri). It was also noticeable that CAT activity was not detected in most of the saprophytic strains, whereas it was present in nearly all pathogenic strains analysed. This observation confirms a previous report by Corin et al. (1978).

\section{Genetic relationships between ETs}

The 30 strains included in this study were distributed among 25 ETs (Table 3 ), each representing a particular combination of alleles for the 12 loci considered. ETs comprising several isolates all belonged to the same species, $L$. interrogans. The 11 strains analysed in that species were shared among six ETs, ET1 comprising four strains (icterohaemorrhagiae RGA, bratislava Jez-Bratislava, lai Lai and hardjo Hardjoprajitno) and ETs 2 and 3 each comprising two strains (autumnalis Akiyami A and canicola Hond Utrecht IV, and bataviae Van Tienen and pyrogenes Salinem, respectively) (Figs 1 and 2, Table 1). Estimation of the genetic relationships between ETs is summarized on the dendrogram in Fig. 1. Each species was clustered individually, except $L$. inadai and L. meyeri. Maximum genetic distances at the intraspecific level varied from 0.18 (L. santarosai and L. kirschneri) to 0.42 ( $L$. borgpetersenii), which is largely consistent with the distance of 0.60 to 0.70 commonly accepted as delimiting different species (Boerlin et al., 1991). No cluster of pathogenic species was obvious from the data obtained by MEE in the present study, although 
M. Letocart and others

Table 3. Allele profiles of 25 ETs of Leptospira species

\begin{tabular}{|c|c|c|c|c|c|c|c|c|c|c|c|c|}
\hline \multirow[b]{2}{*}{ ET } & \multicolumn{12}{|c|}{ No. of alleles at the enzyme loci } \\
\hline & $\mathrm{ACO}$ & ADK & ALP & CAT & FUM & GD2 & IDH & MDH & MPI & PEP4 & PEP5 & PGI \\
\hline 1 & 2 & 7 & 8 & 2 & 5 & 5 & 2 & 2 & 4 & 4 & 3 & 5 \\
\hline 2 & 2 & 7 & 8 & 2 & 5 & 5 & 2 & 2 & 4 & 4 & 4 & 5 \\
\hline 3 & 2 & 7 & 8 & 2 & 5 & 5 & 2 & 2 & 4 & 5 & 3 & 5 \\
\hline 4 & 2 & 7 & 8 & 2 & 5 & 4 & 2 & 1 & 4 & 5 & 4 & 5 \\
\hline 5 & 2 & 7 & 8 & 0 & 5 & 4 & 2 & 2 & 8 & 4 & 4 & 5 \\
\hline 6 & 2 & 5 & 1 & 1 & 5 & 3 & 4 & 2 & 11 & 11 & 7 & 0 \\
\hline 7 & 2 & 5 & 2 & 1 & 5 & 2 & 4 & 3 & 5 & 8 & 7 & 7 \\
\hline 8 & 2 & 6 & 1 & 1 & 5 & 3 & 4 & 2 & 11 & 0 & 7 & 7 \\
\hline 9 & 2 & 5 & 1 & 1 & 5 & 3 & 4 & 2 & 11 & 11 & 7 & 7 \\
\hline 10 & 1 & 6 & 6 & 2 & 5 & 2 & 2 & 2 & 3 & 1 & 2 & 8 \\
\hline 11 & 1 & 5 & 6 & 0 & 5 & 1 & 2 & 2 & 3 & 1 & 2 & 8 \\
\hline 12 & 2 & 7 & 10 & 2 & 5 & 5 & 2 & 2 & 1 & 5 & 3 & 1 \\
\hline 13 & 3 & 7 & 10 & 2 & 5 & 5 & 2 & 2 & 1 & 7 & 2 & 2 \\
\hline 14 & 3 & 7 & 5 & 3 & 2 & 5 & 2 & 2 & 3 & 11 & 4 & 3 \\
\hline 15 & 3 & 7 & 5 & 0 & 2 & 5 & 2 & 2 & 3 & 12 & 5 & 3 \\
\hline 16 & 2 & 1 & 3 & 2 & 5 & 5 & 2 & 2 & 6 & 10 & 5 & 5 \\
\hline 17 & 3 & 5 & 9 & 0 & 2 & 7 & 3 & 3 & 2 & 1 & 3 & 6 \\
\hline 18 & 2 & 7 & 8 & 2 & 5 & 4 & 2 & 2 & 4 & 6 & 3 & 5 \\
\hline 19 & 2 & 7 & 8 & 2 & 3 & 4 & 2 & 2 & 4 & 13 & 4 & 5 \\
\hline 20 & 2 & 6 & 1 & 2 & 5 & 3 & 4 & 2 & 11 & 11 & 7 & 7 \\
\hline 21 & 2 & 7 & 8 & 2 & 5 & 4 & 2 & 2 & 4 & 13 & 4 & 5 \\
\hline 22 & 1 & 2 & 0 & 0 & 3 & 8 & 1 & 1 & 5 & 8 & 0 & 4 \\
\hline 23 & 1 & 4 & 0 & 0 & 2 & 8 & 1 & 1 & 7 & 8 & 0 & 4 \\
\hline 24 & 3 & 7 & 6 & 0 & 6 & 6 & 3 & 3 & 4 & 2 & 1 & 2 \\
\hline 25 & 1 & 3 & 0 & 0 & 1 & 7 & 3 & 2 & 10 & 3 & 8 & 5 \\
\hline
\end{tabular}

Genetic distance

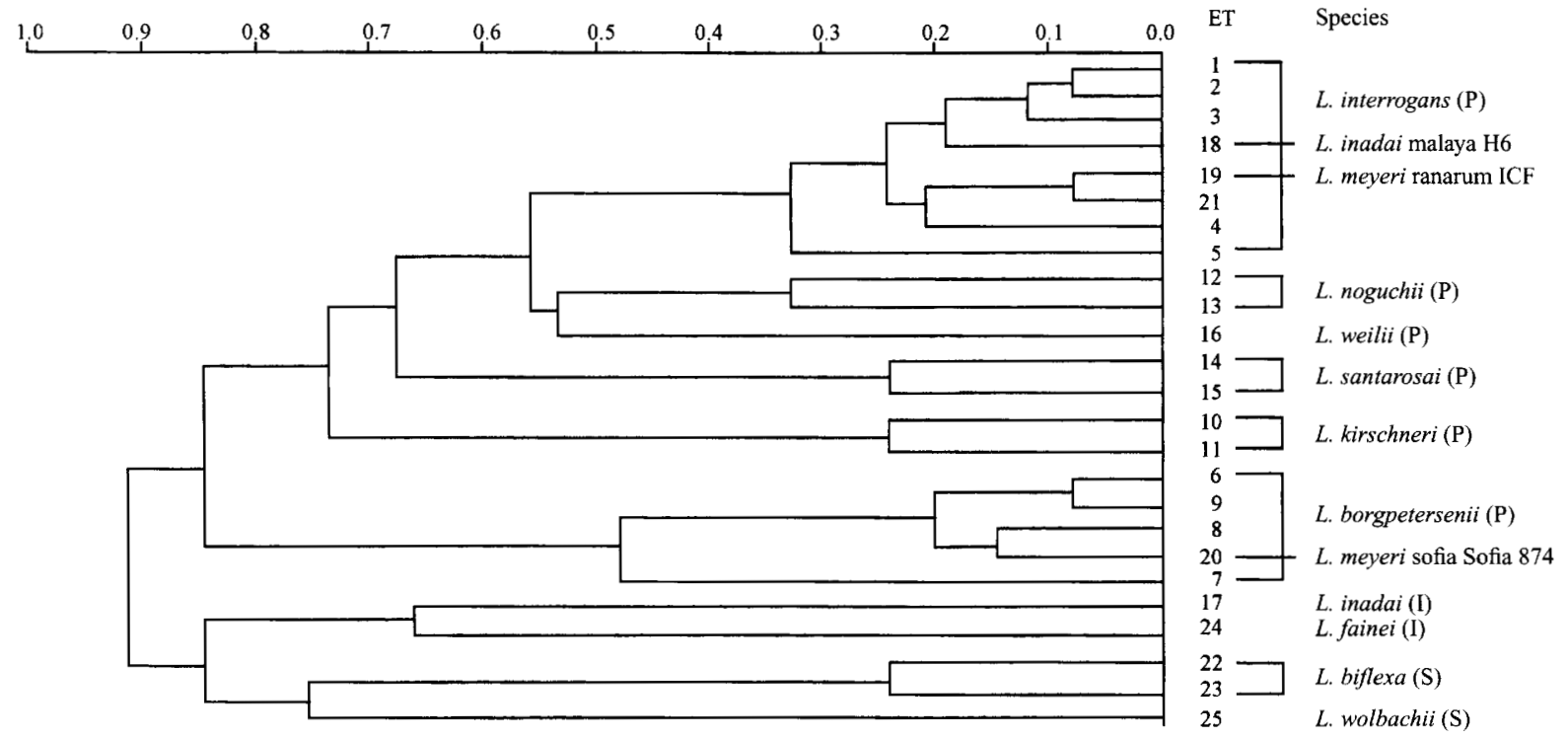

Fig. 1. Dendrogram representing the genetic relationships within the genus Leptospira. The tree was generated by the average-linking method of clustering from a matrix of pairwise coefficients of genetic distances between ETs. See Table 1 for correspondence between ETs and strains. Taxonomic uncertainties for ETs 18, 19 and 20 are discussed in the text. P, Pathogen; I, intermediate; S, saprophyte. 


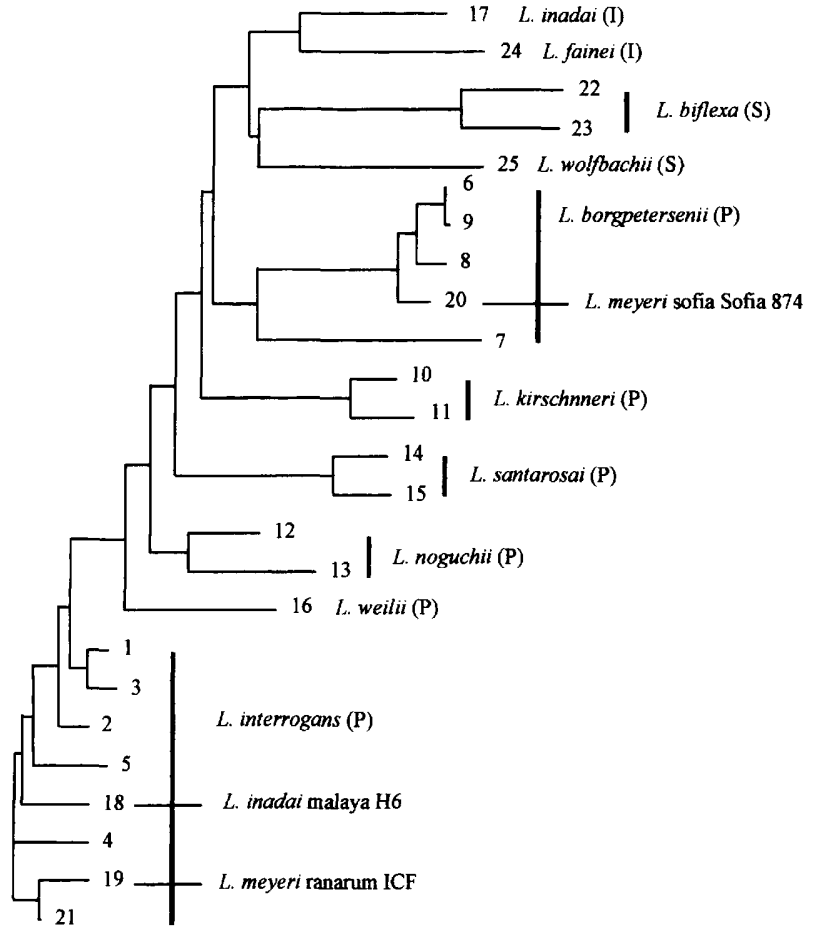

Fig. 2. Dendrogram representing the genetic relationships within the genus Leptospira. The tree was generated by the neighbour-joining method. ET numbers are given at the ends of the branches (see Table 1 for correspondence with strains). Taxonomic uncertainties for ETs 18,19 and 20 are discussed in the text. P, Pathogen; I, intermediate; S, saprophyte.

the pathogenic species appeared genetically separated from intermediate ( $L$. inadai and $L$. fainei) and saprophytic species.

\section{Gene linkage disequilibrium}

None of the pairs of loci examined showed a statistically significant departure from random recombination, as expected for a non-clonal population structure (data not shown).

\section{DISCUSSION}

The polymorphism of the genus Leptospira has been demonstrated by several studies (Ralph et al., 1993; Ramadass et al., 1992; Yasuda et al., 1987) and is confirmed by the present MEE analysis. All loci considered in the present study were polymorphic with a mean number of alleles of $6 \cdot 5$, which is comparable to that found for organisms like Aeromonas (Altwegg et al., 1991) or Campylobacter (Aeschbacher \& Piffaretti, 1989), with respective mean values of 6.5 and 6.9 . Others, like Mycobacterium (Wasem et al., 1991) and Borrelia (Boerlin et al., 1992) seem to have less allelic diversity, with respective calculated mean values of $2 \cdot 8$ and 5.9. In contrast, the genus Listeria appears to be more polymorphic, with a mean number of alleles per locus of 9.5 (Boerlin et al., 1991).

The mean genetic diversity within the genus Leptospira is 0.63 , which is equal to that found for Campylobacter (Aeschbacher \& Piffaretti, 1989) and comparable to the values of 0.64 for Treponema (Lymbery et al., 1990) and Aeromonas (Altwegg et al., 1991) or 0.67 for Borrelia (Boerlin et al., 1992).

The $L$. interrogans cluster is relatively heterogeneous, the 11 strains studied being dispersed among six different ETs. On the other hand, some strains could not be separated under the conditions used in this investigation. This reflects the ambivalent nature of this species, which exhibits at the same time some heterogeneity and some homogeneity, as already suspected from studies of the organization of the Leptospira genome (Herrmann et al., 1991). The fact that this species was the only one in which ETs with multiple strains were observed is very interesting, as it suggests that the species of this genus could have different population dynamics. This possibility should be investigated by the analysis of more strains in the species concerned. Determination of linkage disequilibrium within the $L$. interrogans population suggests a possible lack of clonality within the species (Brown et al., 1980), as no pair of loci showed significant disequilibrium. If this is confirmed by the analysis of a larger number of strains and loci, it should be interpreted as the consequence of a non-clonal population structure and would involve sufficiently frequent chromosomal rearrangements that no important linkage disequilibrium appears in these bacteria (Krawiec \& Riley, 1990; Wasem et al., 1991). This hypothesis could be supported by the presence of intervening sequences in the genomes of these bacteria, which would testify for their potential plasticity (BoursauxEudes et al., 1995; Zuerner, 1993), and will stimulate research into possible transfers of DNA between Leptospira, a domain which is still little explored (Saint Girons et al., 1990). If recombinational events are relatively frequent in the genomes of these bacteria, ETs comprising multiple strains could be the consequence of a relatively recent divergence of the strains concerned (Maynard Smith et al., 1993), which could be distinguished by PFGE (Herrmann et al., 1991, 1992) and AP-PCR. Nevertheless, care must be taken in the interpretation of these results, since linkage disequilibrium was calculated on a limited sample and more strains should be studied to confirm definitively the population structure of the species $L$. interrogans.

Two strains unrelated to $L$. interrogans were strongly integrated in its cluster. One of these was ranarum ICF, the type strain of the species L. meyeri, for which such a situation has already been observed. This strain was designated as representing a new species by Yasuda et al. (1987), while it had been previously recognized as an $L$. interrogans strain by Brendle $e t$ al. (1974). Similarly, rrs gene sequencing (Hookey, 1992; Hookey et al., 1993), as well as PCR studies (Murgia et 
al., 1997), revealed that strain ICF clustered with the pathogenic species. Its inclusion in the $L$. interrogans cluster by MEE was expected, since analysis of this strain in this laboratory, by molecular techniques including ribotyping (Perolat et al., 1993), AP-PCR (Ralph et al., 1993), MRSP (Ralph et al., 1993) and species-specific probing (Letocart et al., 1997), was always consistent with its assignment to $L$. interrogans . Indeed, for strain ICF, with the exception of Yasuda et al. (1987), who defined it as the type strain of L. meyeri, all other molecular studies (Gravekamp et al., 1993; Hookey, 1992; Hookey et al., 1993; Letocart et al., 1997; Murgia et al., 1997; Segers et al., 1992) have assigned it to the pathogenic group. In the case of malaya $\mathrm{H6}$, the results of MEE were once more in agreement with previous typing in this laboratory: this strain was recognized by a specific probe directed against $L$. interrogans (Letocart et al., 1997) and its ribotype was identical to those of other strains known to belong to the L. interrogans species according to DNA-DNA hybridization (Brenner \& Kaufmann, 1994; Perolat et al., 1993). Lastly, these two strains share the same allele at the ALP locus with the $L$. interrogans strains, an allele not encountered in any other species in the present study. Heterogeneity among culture collections of reference strains is a more credible explanation for these discrepancies.

Information given by the trees in Figs 1 and 2 on the phylogeny of the genus generally confirms the coherence of the species delineation as established by DNA-DNA hybridization. This was not true, however, for the two species L. meyeri and L. inadai, strains of which were scattered on the trees. The case of the reference strain of L. meyeri (ranarum strain ICF) has been discussed above; the second strain, sofia Sofia 874 , was distant from the former. Instead of representing the species $L$. meyeri in a separate cluster, it definitely belongs to the $L$. borgpetersenii cluster. In addition, strain Sofia 874 had identical alleles to the $L$. borgpetersenii strains at the IDH and PEP5 loci, which were monomorphic and specific to this species. When hybridized to species-specific probes (Letocart et al., 1997), sofia Sofia 874 was recognized by the probe directed against $L$. borgpetersenii strains and not by another probe directed against the two species $L$. interrogans and L. meyeri (Letocart et al., 1997). These results are also in agreement with ribotyping (Perolat et al., 1993), where sofia Sofia 874 had the same ribotype as nona Nona, identified as an $L$. borgpetersenii strain by DNA-DNA hybridization (Brenner \& Kaufmann, 1994). Similarly, PCR studies were in agreement with classification of strain sofia Sofia 874 among the pathogenic leptospires (Murgia et al., 1997).

$L$. inadai and $L$. fainei are characterized by an intermediate response to the phenotypic characters used to distinguish pathogens and saprophytes (growth at $30^{\circ} \mathrm{C}$ with 8 -azaguanine and growth at $13^{\circ} \mathrm{C}$ ), which suggests a separate genetic status in view of these results. The cluster analysis also seems to be in agreement with the close relationship previously suggested between $L$. inadai and L. fainei (Perolat et al., 1998).

Concerning the comparison between pathogenic and saprophytic species, the species of the two groups are distinguished genetically on the two trees and $L$. inadai and $L$. fainei, which are phenotypically intermediate, seem to be separated genetically from both pathogens and non-pathogens and closer to the saprophytes (Figs 1 and 2). The topologies of the trees seem to be in agreement with the hypothesis that the saprophytic leptospires are the most ancestral, from which the intermediate and pathogenic strains could have been derived by the acquisition of pathogenic characteristics.

In conclusion, the main contribution of this study is the demonstration of a close correlation between the results of MEE and those obtained by other molecular methods, in particular DNA-DNA hybridization. The data presented here provide a clear picture of the heterogeneity of the genus Leptospira at the species and subspecies levels. Genetic distinction between pathogenic and saprophytic species is evident on both trees, confirming previous reports related to $r$ rs gene sequencing (Hookey et al., 1993). An important taxonomic question exhibited by this work is the accuracy of the delineation and positioning of the two species $L$. meyeri and $L$. inadai. The case of $L$. meyeri has been discussed extensively here and elsewhere (Letocart et al., 1997), with the same conclusion that there must be collection discrepancies that should be taken into account by the reference laboratories and resolved finally by the comparative typing of samples of these strains originating from reference laboratories. In the case of $L$. inadai, the lack of molecular characterization of serovars related to this species necessitates a comprehensive taxonomic investigation to clarify the status of these strains. The need for such studies is supported by rrs gene sequencing data confirming heterogeneity among the world collections of leptospires (D. Postic, personal communication), which seems responsible for the discrepancies concerning $L$. meyeri and $L$. inadai members.

This initial work with MEE that focused on a representative set of strains should be considered as the basis for a comprehensive and new approach of the study of the genetic structure of the genus Leptospira. Further investigations including additional reference strains from serovars of public health interest will contribute to knowledge of the taxonomy of these bacteria.

\section{ACKNOWLEDGEMENTS}

M.L. was the recipient of a scholarship from the French Ministry of Research and Technology and from the South Province of New Caledonia. P.P. and M.L. were supported by the International Network of Pasteur Institutes (General Delegation, Institute Pasteur, Paris). Thanks are due to P. A. D. Grimont for his constant interest in this work. 


\section{REFERENCES}

Aeschbacher, M. \& Piffaretti, J.-C. (1989). Population genetics of human and animal enteric Campylobacter strains. Infect Immun 57, 1432-1437.

Altwegg, M., Reeves, M. W., Altwegg-Bissig, R. \& Brenner, D. J. (1991). Multilocus enzyme analysis of the genus Aeromonas and its use for species identification. Zentbl Bakteriol 275, 28-45.

Beutin, L., Ørskov, I., Ørskov, F., Zimmermann, S., Prada, J., Gelderblom, H., Stephan, R. \& Whittam, T. S. (1990). Clonal diversity and virulence factors in strains of Escherichia coli of the classic enteropathogenic serogroup O114. J Infect Dis 162, 1329-1334.

Boerlin, P. (1997). Applications of multilocus enzyme electrophoresis in medical microbiology. $J$ Microbiol Methods 28, 221-231.

Boerlin, P., Rocourt, J. \& Piffaretti, J.-C. (1991). Taxonomy of the genus Listeria by using multilocus enzyme electrophoresis. Int $J$ Syst Bacteriol 41, 59-64.

Boerlin, P., Peter, O., Bretz, A. G., Postic, D., Baranton, G. \& Piffaretti, J.-C. (1992). Population genetic analysis of Borrelia burgdorferi isolates by multilocus enzyme electrophoresis. Infect Immun 60, 1677-1683.

Boursaux-Eude, C., Saint Girons, I. \& Zuerner, R. (1995). IS1500, an IS3-like element from Leptospira interrogans. Microbiology 141, 2165-2173.

Brendle, J. J., Rogul, M. \& Alexander, A. D. (1974). DNA hybridization among selected leptospiral serotypes. Int $J$ Syst Bacteriol 25, 205-214.

Brenner, D. J. \& Kaufmann, A. F. (1994). DNA relatedness of Leptospiraceae serovars. Leptospira molecular biology home page.

http://www.pasteur.fr/Bio/Leptospira/Leptospira.html/

Brown, A. H. D., Feldman, M. W. \& Nevo, E. (1980). Multilocus structure of natural populations of Hordeum spontaneum. Genetics 96, 523-536.

Corin, R. E., Boggs, E. \& Cox, C. D. (1978). Enzymatic degradation of $\mathrm{H}_{2} \mathrm{O}_{2}$ by Leptospira. Infect Immun 22, 672-675.

Dikken, H. \& Kmety, E. (1978). Serological typing methods of leptospires. Methods Microbiol 11, 259-307.

Ellinghausen, H. C. \& McCullough, W. G. (1965). Nutrition of Leptospira pomona and growth of 13 other serotypes: fractionation of oleic albumin complex and a medium of bovine albumin and polysorbate 80. Am J Vet Res 26, 45-51.

Ellis, W. A., Montgomery, J. M. \& Thiermann, A. B. (1991). Restriction endonuclease analysis as a taxonomic tool in the study of pig isolates belonging to the Australis serogroup of Leptospira interrogans. J Clin Microbiol 29, 957-961.

Gravekamp, C., Van de Kemp, H., Franzen, M., Carrington, D., Schoone, G. J., Van Eys, G. J. J. M., Everard, C. O. R., Hartskeerl, R. A. \& Terpstra, W. J. (1993). Detection of seven species of pathogenic leptospires by PCR using two sets of primers. $J$ Gen Microbiol 139, 1691-1700.

Harris, H. \& Hopkinson, D. A. (1976). Handbook of Enzyme Electrophoresis in Human Genetics. New York: Elsevier.

Herrmann, J. L., Baril, C., Bellenger, E., Perolat, P., Baranton, G. \& Saint Girons, I. (1991). Genome conservation in isolates of Leptospira interrogans. J Bacteriol 173, 7582-7588.

Herrmann, J. L., Bellenger, E., Perolat, P., Baranton, G. \& Saint Girons, I. (1992). Pulsed-field gel electrophoresis of NotI digests of leptospiral DNA: a new rapid method of serovar identification. J Clin Microbiol 30, 1696-1702.
Hookey, J. V. (1992). Detection of Leptospiraceae by amplification of $16 \mathrm{~S}$ ribosomal DNA. FEMS Microbiol Lett 90 , 267-274.

Hookey, J. V., Bryden, J. \& Gatehouse, L. (1993). The use of $16 \mathrm{~S}$ rDNA sequence analysis to investigate the phylogeny of Leptospiraceae and related spirochaetes. J Gen Microbiol 139, 2585-2590.

Johnson, R. C. \& Faine, S. (1984). Family II. Leptospiraceae. In Bergey's Manual of Systematic Bacteriology, vol. 1, pp. 62-67. Edited by N. R. Krieg \& J. G. Holt. Baltimore: Williams \& Wilkins.

Krawiec, S. \& Riley, M. (1990). Organization of the bacterial chromosome. Microbiol Rev 54, 503-539.

Letocart, M., Baranton, G. \& Perolat, P. (1997). Rapid identification of pathogenic Leptospira species (Leptospira interrogans, $L$. borgpetersenii, and L. kirschneri) with species-specific DNA probes produced by arbitrarily primed PCR. J Clin Microbiol 35, 248-253.

Lymbery, A. J., Hampson, D. J., Hopkins, R. M., Combs, B. \& Mhoma, J. R. L. (1990). Multilocus enzyme electrophoresis for identification and typing of Treponema hyodysenteriae and related spirochaetes. Vet Microbiol 22, 89-99.

Maynard Smith, J., Smith, N. H., O'Rourke, M. \& Spratt, B. G. (1993). How clonal are bacteria? Proc Natl Acad Sci USA 90 , 4384-4388.

Murgia, R., Riquelme, N., Baranton, G. \& Cinco, M. (1997). Oligonucleotides specific for pathogenic and saprophytic Leptospira occurring in water. FEMS Microbiol Lett 148, 27-34.

Patton, C. M., Wachsmuth, I. K., Evins, G. M., Kiehlbauch, J. A., Plikaytis, B. D., Troup, N., Tompkins, L. \& Lior, H. (1991). Evaluation of 10 methods to distinguish epidemic-associated Campylobacter strains. J Clin Microbiol 29, 680-688.

Perolat, P., Lecuyer, I., Postic, D. \& Baranton, G. (1993). Diversity of ribosomal DNA fingerprints of Leptospira serovars provides a database for subtyping and species assignation. Res Microbiol 144, 5-15.

Perolat, P., Merien, F., Ellis, W. A. \& Baranton, G. (1994). Characterization of Leptospira isolates from serovar hardjo by ribotyping, arbitrarily primed PCR, and mapped restriction site polymorphisms. J Clin Microbiol 32, 1949-1957.

Perolat, P., Chappel, R. J., Adler, B., Baranton, G., Bulach, D. M., Billinghurst, M. L., Letocart, M., Merien, F. \& Serrano, M. S. (1998). Leptospira fainei sp. nov., isolated from pigs in Australia. Int J Syst Bacteriol 48, 851-858.

Ralph, D., McClelland, M., Weish, J., Baranton, G. \& Perolat, P. (1993). Leptospira species categorized by arbitrarily primed polymerase chain reaction (PCR) and by mapped restriction polymorphisms in PCR-amplified rRNA genes. J Bacteriol 175 , 973-981.

Ramadass, P., Jarvis, B. D. W., Corner, R. J., Penny, D. \& Marshall, R. B. (1992). Genetic characterization of pathogenic Leptospira species by DNA hybridization. Int J Syst Bacteriol 42, 215-219.

Raymond, M. \& Rousset, F. (1995). GENEPOP version 1.2: population genetics software for exact tests and ecumenicism. $J$ Hered 86, 248-249.

Saint Girons, I., Margarita, D., Amouriaux, P. \& Baranton, G. (1990). First isolation of bacteriophages for a spirochaete: potential genetic tools for Leptospira. Res Microbiol 141, 1131-1138.

Saitou, N. \& Nei, M. (1987). The neighbor-joining method: a new method for reconstructing phylogenetic trees. Mol Biol Evol 4, $406-425$. 
Segers, R. P. A. M., van Gestel, J. A., van Eys, G. J. J. M., van der Zeijst, B. A. M. \& Gaastra, W. (1992). Presence of putative sphyngomyelinase genes among members of the family Leptospiraceae. Infect Immun 60, 1707-1710.

Selander, R. K., Caugant, D. A., Ochman, H., Musser, J. M., Gilmour, N. M. \& Whittam, T. S. (1986). Methods of multilocus enzyme electrophoresis for bacterial population genetics and systematics. Appl Environ Microbiol 51, 873-884.

Selander, R. K., Beltran, P., Smith, N. H., Barker, R. M., Crichton, P. B., Old, D. C., Musser, J. M. \& Whittam, T. S. (1990). Genetic population structure, clonal phylogeny, and pathogenicity of Salmonella paratyphi B. Infect Immun 58, 1891-1901.

Takezaki, N. \& Nei, M. (1996). Genetic distances and reconstruction of phylogenetic trees from microsatellite DNA. Genetics 144, 389-399.
Wasem, C. F., McCarthy, C. M. \& Murray, L. W. (1991). Multilocus enzyme electrophoresis analysis of the Mycobacterium avium complex and other mycobacteria. J Clin Microbiol 29, 264-271.

Yakrus, M. A., Reeves, M. W. \& Hunter, S. B. (1992). Characterization of isolates of Mycobacterium avium serotypes 4 and 8 from patients with AIDS by multilocus enzyme electrophoresis. $J$ Clin Microbiol 30, 1474-1478.

Yasuda, P. H., Steigerwalt, A. G., Sulzer, K. R., Kaufmann, A. F., Rogers, F. \& Brenner, D. J. (1987). Deoxyribonucleic acid relatedness between serogroups and serovars in the family Leptospiraceae with proposals for seven new Leptospira species. Int J Syst Bacteriol 37, 407-415.

Zuerner, R. (1993). Nucleotide sequence analysis of IS 1533 from Leptospira borgpetersenii: identification and expression of two IS-encoded proteins. Plasmid 31, 1-11. 